Cytogenet Genome Res 1986;43:1

\title{
Announcements
}

\section{Ninth International Workshop on Human Gene Mapping}

Paris, September 6-11, 1987 First announcement

The Ninth International Workshop on Human Gene Mapping will be held from September 6th to 11th, 1987, in Paris, France. It will be followed by an open conference on New Genetics and the Gene Map of Man which will be held on September 11th (afternoon) and 12th.

To be placed on the mailing list for future announcements or for further information about the conference, please write to:

HGM9 c/o Professeur Jean Frézal Hôpital des Enfants-Malades 149, rue de Sevres 75743 Paris Cedex 15 (France)

Interested persons are kindly requested to note that for an interim assignment of alphanumeric symbols or "D numbers" for anonymous DNA segments they have to contact:

Dr. K.K. Kidd

Human Gene Mapping Library

$1050 \mathrm{KBT}$, Yale University

260 Whitney Avenue

New Haven, CT 06511 (USA)

Those researchers who map genes in species other than human, please transmit your data to:

Dr. P.A. Lalley Institute for Medical Research 110 Hospital Drive Bennington, VT 05201 (USA) In order to gather all the pertinent literature on mapping, authors are kindly requested to send a reprint of their papers to the HGM9 mailing address above. 